\title{
LA DIVERSIDAD DE LOS PAISAJES DE FRUTICULTURA EN EL BIERZO: LA PUJANZA DE LOS REGADÍOS DE MANZANOS Y PERALES Y LA CONSERVACIÓN DE “LOS SOTOS” DE CASTAÑOS
}

\author{
José María SAN ROMÁN RODRÍGUEZ \\ Departamento de Geografía y Geología-Universidad de León
}

Recibido: 10/03/2011

Aceptado: 19/07/2011

RESUMEN: Las condiciones climáticas de la fosa tectónica de El Bierzo favorecen los cultivos leñosos, especialmente la fruticultura. Este paisaje agrario se moderniza e intensifica en los años 1960 con la construcción de dos canales de regadío. La fruticultura de pepita, manzanos y perales, la de hueso con los cerezos y la de frutos secos, con las castañas concentra las principales producciones. Un paisaje en el que los productos agrícolas con marcas de calidad pera conferencia, manzana reineta y castañas concentran las principales producciones. Este paisaje ha sido muy valorado por los autores bercianos, como Gil y Carrasco.

PALABRAS CLAVE: Bierzo, Regadío, Fruticultura, Producción de calidad.

THE DIVERSITY OF THE LANDSCAPE OF THE FRUIT CROPS IN EL BIERZO, THE STRENGTH OF THE IRRIGATION OF APPLE AND PEAR TREES AND THE PRESERVATION OF THE "SOTOS" OF CHESTNUTS TREES

ABSTRACT: The climatic conditions in the tectonic depression of El Bierzo are favourable to tree-growing, especially the cultivation of fruit-trees. This agricultural landscape was modernized and cultivation intensified in the 1960s when two irrigation canals were constructed. The growing of pomaceous fruits, such as apples and pears, of drupes or stone fruits, such as cherries, and of nuts, such as chestnuts, comprises the principal products. Such crops dominate a landscapeThe climatic conditions in the tectonic depression of El Bierzo are favourable to tree-growing, especially the cultivation of fruit-trees. This agricultural landscape was modernized and cultivation intensified in the 1960s when two irrigation canals were constructed. The growing of pomaceous fruits, such as apples and pears, of drupes or stone fruits, such as cherries, and of nuts, such as chestnuts, comprises the principal products. Such crops dominate a landscape in which most agricultural produce is of items with a quality mark, particularly Conference pears, Reinette apples and chestnuts. The scenery of this area has been greatly praised in literary works, such as those of the nineteenth-century novelist Gil

\footnotetext{
${ }^{1}$ Proyecto de Investigación: "Las unidades basicas de paisaje agrario en españa: identificacion, delimitacion, caracterizacion y valoracion. la España Atlántica y Navarra”. Referencia: CSO2009-12225-C05-04
} 
y Carrasco in which most agricultural produce is of items with a quality mark, particularly Conference pears, Reinette apples and chestnuts. The scenery of this area has been greatly praised in literary works, such as those of the nineteenth-century novelist Gil y Carrasco.

KEY WORDS: Bierzo, Irrigated land, Fruit-growing, Quality production.

\section{INTRODUCCIÓN}

La comarca de El Bierzo es una fosa tectónica delimitada por un cíngulo montañoso. El paisaje agrario sorprendía a los peregrinos que se dirigían a Santiago de Compostela después de abandonar los campos de cereales de la cuenca del Duero y los Montes de León en el descenso hacia la fosa tectónica de El Bierzo por la fertilidad de los cultivos en esta zona hundida con unas condiciones climáticas y edáficas favorables para los cultivos leñosos.

El policultivo tradicional del espacio agrario con viñedo, fruticultura, hortalizas y algunos cereales se ha reducido progresivamente y tiende a concentrarse en los cultivos leñosos. El espacio de fruticultura muestra dos zonas contrastadas las de regadío con cultivos más intensivos y modernizados y las de secano con cultivos en algunos casos en regresión como el castaño y en menor medida los cerezos.

El espacio de estudio que analizamos coincide con la comarca agraria de El Bierzo, con 36 muncipios $^{2}$, con una extensión de 2.824,57 Km2, excluyendo dos municipios de la delimitación que establece la Ley de la Comarca de El Bierzo de 21 de diciembre de 2010, que son Benuza y Palacios del Sil. Se localizan en la periferia montañosa y su integración se debe más a una delimitación como comarca funcional que a las características del medio ecológico; están dentro del área de influencia de la ciudad de Ponferrada.

Los paisajes agrícolas de fruticultura corresponden con las zonas de menor altitud de 400 a 500 metros y de topografía de formas planas, con suaves ondulaciones; tienen los suelos más fértiles de materiales sedimentarios, en las zonas más bajas con las terrazas fluviales y de condiciones climáticas más favorables para la agricultura, mapa 1., coinciden con los paisajes agrarios cultivados con mayor esmero.

\footnotetext{
${ }^{2}$ Arganza, Balboa, Barjas, Bembibre, Berlanga del Bierzo, Borrenes, Cabañas Raras, Cacabelos, Camponaraya, Candín, Carracedelo, Carucedo, Castropodame, Congosto, Corullón, Cubillos del Sil, Fabero, Folgoso de la Ribera, Igüeña, Molinaseca, Noceda, Oencia, Páramo del Sil, Peranzanes, Ponferrada, Priaranza del Bierzo, Puente de Domingo Flórez, Sancedo, Sobrado, Toreno, Torre del Bierzo, Trabadelo, Vega de Espinareda, Vega de Valcarce, Villadecanes, Villafranca del Bierzo.
} 
Los principales cultivos agrícolas son los leñosos, entre los que predominan los frutales, que incluyen diversidad de especies (manzano, peral, cerezo, castaño, guindo, higuera, olivo, almendro, albaricoquero, etc.). En este trabajo nos centraremos en las cuatro especies frutícolas que ocupan más espacio y alcanzan un valor económico más elevado en la comarca y tienen más relevancia: manzano, peral, cerezo y castaño. Debemos indicar que se ha incluido el castaño porque en la comarca predomina la orientación en las plantaciones para la producción de su fruto, las castañas, en un elevado porcentaje. Quedan excluidas del análisis las zonas de los castaños "bravos" dedicadas a la producción de madera, con mayor densidad de árboles por superficie pero que ocupan una superficie más reducida y actualmente están mayoritariamente abandonadas.

Predominan las plantaciones de los castaños formando "sotos" que se caracterizan porque cada pie está a una distancia de 12-15 metros de distancia, necesaria para una adecuada iluminación de las ramas y sobre todo en los extremos que es donde más producen. Estos sotos dedicados a la producción de fruto requieren unos trabajos culturales de poda, injerto, desbroce o incluso cultivo del suelo en los períodos que era necesario ampliar las zonas de cultivo. La gestión de los soutos trata de conseguir elevados rendimientos en las cosechas del fruto; se realizan labores de poda y se injertan con las variedades más rentables. Las cosechas de este fruto son bastante regulares, todos los años se obtienen aunque las condiciones climáticas no sean muy favorables. Por lo tanto dentro de las explotaciones de autoconsumo era una forma de solucionar el problema de la alimentación de personas y ganado, especialmente en algunas áreas en las que las superficies de cultivo son muy limitadas. Además este fruto se puede secar y por lo tanto se conservaba durante todo el año para destinarlo al consumo en la propia explotación y para comercializar en otras zonas. Las castañas se utilizan en algunas celebraciones populares como los magostos y los "maios", fiesta que indica la llegada de la primavera. A todo esto tenemos que añadir que estamos ante la principal zona productora de Castilla y León, lo que ha permitido a las castañas de esta comarca estar amparadas en la Marca de Garantía de Castaña de El Bierzo.

Pero del castaño se aprovechaba todo y de estos soutos se obtiene madera, leña, o materia orgánica para fertilizar los campos de cultivo.

En el paisaje agrario de El Bierzo predominan los cultivos leñosos, viñedo y la fruticultura, dedicaremos el estudio a la fruticultura. Comenzamos con las favorables condiciones ecológicas de la Comarca para estos cultivos y a continuación centramos el estudio en las principales especies frutícolas de regadío que ocupan la zona central de la hoya berciana, manzanos y perales, 
y las zonas de secano en las que predominan los castaños y cerezos. Seguimos con las transformaciones que se han producido en estos paisajes con la especialización agrícola basada en el regadío y en producciones orientadas hacia el mercado mediante marcas de garantía y trazabilidad de las producciones agrarias, finalizamos con la valoración de estos paisajes desde la literatura.

\section{LAS FAVORABLES CONDICIONES ECOLÓGICAS PARA LA FRUTICULTURA: UN CLIMA MEDITERRÁNEO DE INTE- RIOR CON INFLUENCIA ATLÁNTICA}

En la comarca de El Bierzo podemos diferenciar dos unidades la fosa tectónica y las zonas de montaña que la rodean. Este estudio lo centraremos en la fosa alpina que es donde se encuentran los paisajes de fruticultura. Los cultivos agrícolas ocupan el espacio de menor altitud con la topografía más llana y las condiciones climáticas más favorables para los cultivos. Por lo tanto en la "hoya berciana", que recorre el rio Sil y sus afluentes a la que se conectan otras cubetas como la de Bembibre y la de Noceda, donde la agricultura ha dejado muestras desde la Antigüedad del interés por los cultivos leñosos. La altitud, y su influencia en el clima limita estos cultivos en el cíngulo montañoso que cierra esta fosa tectónica unido a otros factores como las mayores pendientes que en algunos casos alcanzan más de 1.600 metros de desnivel entre las zonas más bajas y las más altas, contrastes que han recibido el calificativo de espacio "original" dentro de los bordes de Castilla y León. El bloque hundido está rodeado de montañas en las que la superficie forestal y de prados ocupa mayor extensión y se reducen las de cultivo; tanto en el sur, los Montes Aquilanos y su piedemonte, que de forma abrupta interrumpen una topografía llana a 400 metros de altitud y alcanzan en algunas zonas más de dos mil metros (Cabeza de la Yegua 2.135 metros de altitud), en la zona este se prolonga este bloque levantado con los Montes de León, pero con menos altitud, Puerto del Manzanal/Brañuelas (1.200m.); por el oeste con las estribaciones de la Sierra de Caurel, con valles fluviales muy encajados como el del Selmo de gran potencia erosiva y sin espacio para los cultivos agrícolas, las líneas de cumbres se encuentran en Seo (1.578 metros) que se unen por el norte a los relieves montañosos de la Sierra de Ancares excavados por la red fluvial del Burbia y el Cúa tributarios del Sil, las zonas culminan en Miravalles (1.969 m.) y en la Sierra de Gistredo en el Catoute (REDONDO ET AL., 2002: 91).

Las condiciones climáticas y edáficas en la fosa tectónica son muy favorables para la agricultura, especialmente para los cultivos leñosos. El ciclo vegetativo es más prolongado con temperaturas más elevadas y una reducción del número de días de helada. Esta configuración del relieve aisla a la hoya 
berciana de los vientos fríos, y permite que exista una gran diversidad térmica y pluviométrica en El Bierzo, un clima mediterráneo de interior en las zonas más bajas, que se modifica progresivamente hacia las zonas de la periferia con la altitud, pero que la localización en la zona noroeste peninsular aumenta la humedad con las borrascas que llegan del Atlántico. Estas características climáticas influirán en la distribución de los cultivos leñosos según los periodos de crecimiento y maduración del fruto. Las primeras cosechas de frutas son las de cerezas, a finales de la primavera, y las últimas las de castañas al comenzar el otoño, para precisar las más tempranas maduran en los cerezos a finales de mayo, y en los castaños se recogen los frutos más tardíos a finales de octubre. El período de crecimiento vegetativo de los frutales por lo tanto va a ser distinto, dependiendo de la especie. Este aspecto resulta esencial en la fruticultura de la comarca, porque las variaciones en las condiciones climáticas podían mermar las cosechas de una especie pero, en cambio, no afectaba a otras producciones.

Figura 1. Los municipios de la comarca de El Bierzo

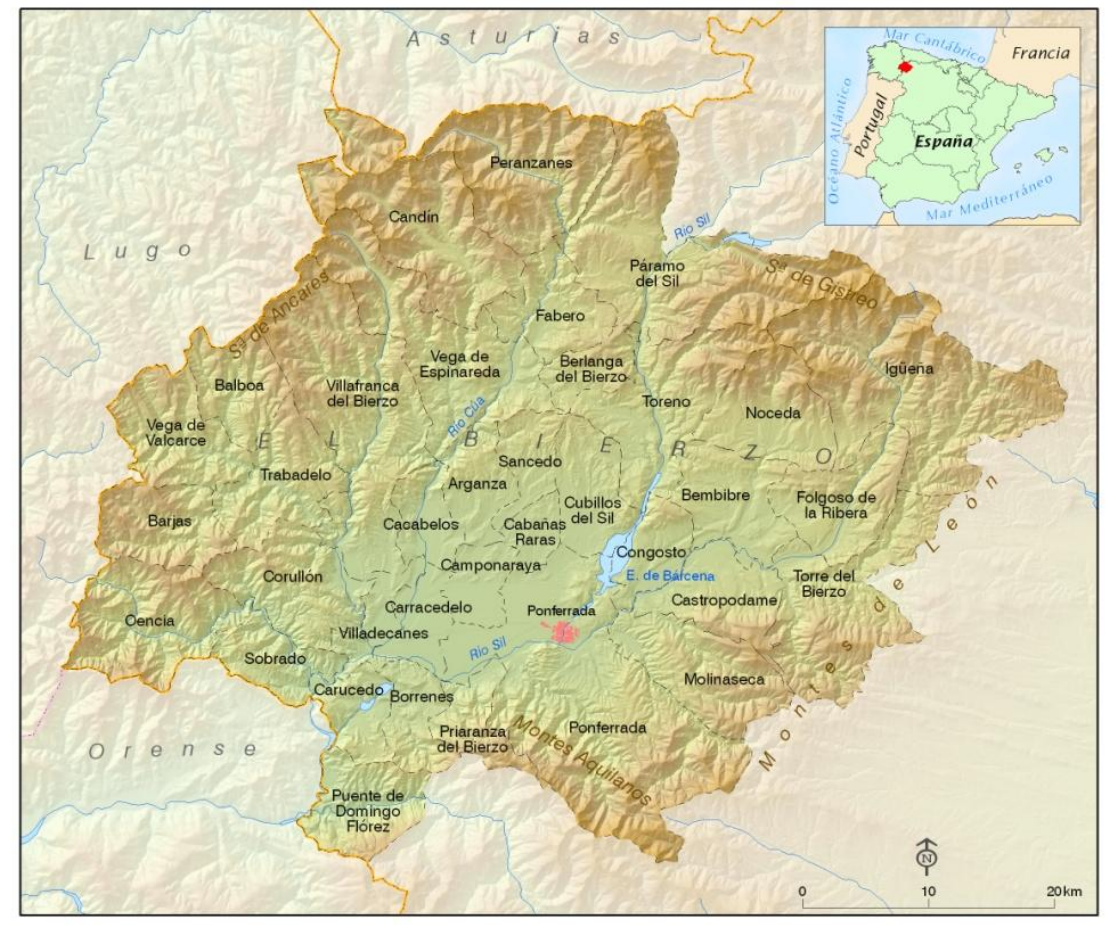


En la fosa alpina, encuentra la estación de Ponferrada a $534 \mathrm{~m}$. de altitud, con $668 \mathrm{~mm}$. de precipitaciones anuales están muy próximas al umbral mínimo de humedad 700 mm. (AGUSTí, 2004: 65) que necesitan la mayoría de los frutales para el cultivo en secano.

Allí las temperaturas alcanzan valores favorables para el cultivo, frío invernal y el calor estival no es muy elevado ni prolongado, la media mensual de las mínimas en enero es de $1,0^{\circ} \mathrm{C}$ y la media mensual de las máximas en julio es de $28,9^{\circ} \mathrm{C}$. Por lo tanto están entre los umbrales óptimos para lograr cosechas de calidad, que los termómetros no desciendan en invierno, en enero por debajo de $\operatorname{los}-5^{\circ} \mathrm{C}$ y las máximas en verano no alcancen valores superiores a los $35^{\circ} \mathrm{C}$. Por lo tanto, están cubiertas las necesidades de frío invernal de los frutales y la subida de los termómetros en verano permite un adecuado crecimiento del fruto y maduración. Cuando las temperaturas alcanzan valores elevados a finales del invierno y comienzos de la primavera, se anticipa el desarrollo de los brotes en los frutales y la floración, aumentando el riesgo de que las heladas produzcan daños en los cultivos.

Pero las condiciones climáticas no afectan de la misma forma a cada especie de frutales. Los cerezos, por ejemplo, tienen una floración más temprana y con frecuencia las heladas merman las cosechas de este fruto, los árboles están en flor cuando las zonas de montaña están cubiertas con un manto de nieve. El período de frío invernal disminuye en la fosa tectónica berciana y permite cultivar diversidad de especies frutales. En la estación termopluviométrica de Ponferrada los días de heladas se reducen a 40, pero también influye la distribución anual en la zona central de la cuenca, resultan muy perjudiciales, como hemos señalado, para todos los frutales durante la primavera.

Estas características climáticas se muestran matizadas a escala local, con la altitud hacia la periferia de la depresión disminuye la temperatura y se incrementan las precipitaciones, el encajamiento de la red fluvial y los embalses aumentan los periodos de nieblas.

También las temperaturas influyen en el proceso de crecimiento y de maduración de los frutos, cuando son elevadas es necesario aumentar la frecuencia de los riegos a los frutales para que las manzanas y peras alcancen el tamaño adecuado y se adelanta el periodo de recogida de las cosechas.

Como hemos señalado, el total de las precipitaciones anuales alcanza los También influye en los cultivos la intensidad y el tipo de precipitaciones. Las tormentas de finales de la primavera y del verano, dos días en mayo y agosto y tres en junio y julio, pueden ser muy perjudiciales para estos culti- 
vos si son de granizo; además pueden facilitar la propagación de plagas en manzanos y perales.

Figura 2. Variables climáticas elementales

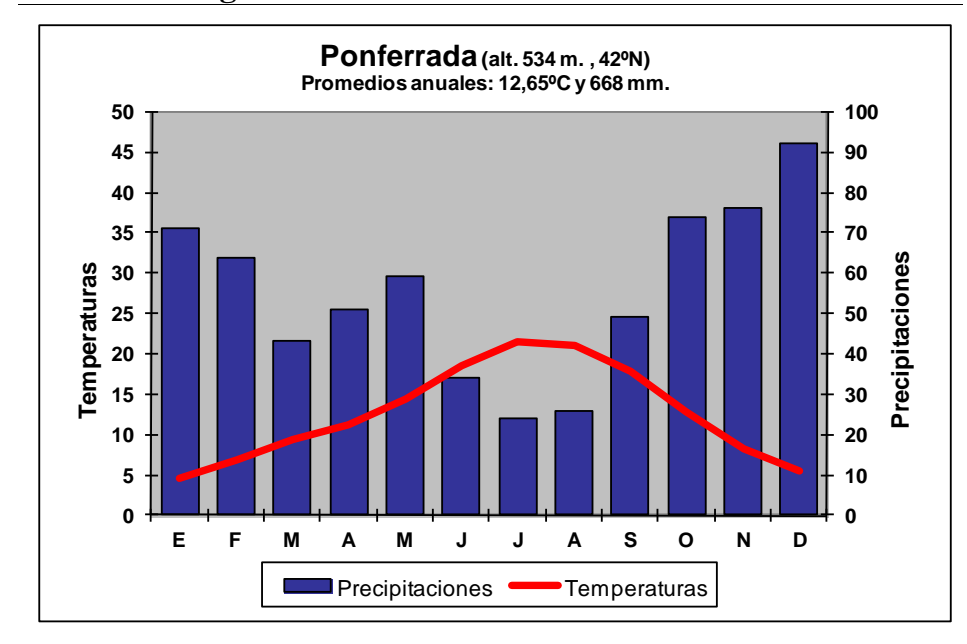

FUENTE: AEMET (1971-2000)

Otros elementos climáticos, como la humedad relativa cuando es muy elevada, favorecen el desarrollo de plagas en las plantaciones de frutales. El número de horas de sol influye en la maduración de los frutos que alcanza en la zona central de la fosa tectónica los 2.113 días de sol, aunque los frutales son poco exigentes en intensidad luminosa, por lo que no condiciona la distribución. La dirección del viento, la velocidad y la frecuencia son rasgos a tener en cuenta. En la fruticultura de pepita el viento es muy negativo cuando se produce en períodos próximos a la cosecha, ya que provoca la caída de los frutos.

Pero la diversidad microclimática de la depresión berciana por los valles fluviales de Sil y sus afluentes Boeza, Cúa y Burbia aumenta en los bordes montañosos. Las precipitaciones son más abundantes y las temperaturas disminuyen, por lo tanto las especies de frutales que necesitan temperaturas más altas como el cerezo no van a desarrollarse en estas zonas. Las precipitaciones anuales pueden alcanzar los 1.460 milímetros, y el período de mínimas precipitaciones el verano, $151 \mathrm{~mm}$., aunque no llega a producirse aridez durante este período. Los meses de invierno son más húmedos, y un elevado porcentaje de las precipitaciones que se reciben son sólidas, en forma de nieve. En estas zonas de mayor altitud desaparece la fruticultura, e incluso el castaño, más resistente a las bajas temperaturas. Los sotos de castaños 
son los que resisten en las zonas más altas hasta los 900 metros de altitud, y en algunas vertientes más abrigadas puede alcanzar altitudes superiores.

En los paisajes agrarios de fruticultura de secano predominan el cerezo y el castaño, y en las zonas de regadío el manzano y el peral. Cuando estos últimos se cultivan en las zonas de secano las cosechas tienen calidades inferiores y son de menor rentabilidad que en las zonas de regadío.

\section{LA TRADICIONAL VINCULACIÓN DEL ESPACIO AGRARIO CON LOS CULTIVOS LEÑOSOS}

La agricultura de la hoya berciana en la Antigüedad ya muestra una orientación hacia los cultivos leñosos. Durante la dominación del noroeste penínsular por el imperio romano al interés por la explotación minera tenemos que añadir el desarrollo de algunos cultivos como del castaño y posiblemente otros frutales, para alimentar a la población dedicada a la minería. En los paisajes agrarios en la Edad Media, aparece la organización del espacio rural en el Bierzo con indicaciones precisas de los linderos de las parcelas en los que se plantan perales, o en otros casos cerca de las viviendas, la existencia de frutales al lado de huertas, viñas y casas muestran una disposición del espacio agrario que con pequeñas variaciones en algunos casos ha pervivido hasta época reciente. En esta etapa aparece regulada la utilización del agua, lo que indica el nivel de organización de la producción agraria y el interés del aprovechamiento para regadío. El testimonio del abad del monasterio de Carracedo en el siglo XVI que impulsa la plantación de frutales y construye un muro de piedra alrededor de la huerta que llega hasta el río Cúa para proteger esta producción agraria, que tenía árboles frutales de varias especies, perales, manzanos, guindos y cerezos, ejemplifica la orientación de la agricultura hacia los cultivos leñosos. También al desarrollo de estos paisajes agrícolas contribuyó el Camino de Santiago que recorre el área de estudio. Pero son los monasterios de Carracedo, Vega de Espinareda, San Pedro de Montes y el Obispado de Astorga que ejercen el control de estas huertas y frutales, los que favorecen esta producción (RODRÍGUEZ ET AL., 1998:72).

En el siglo XVIII las referencias del Catastro del Marqués de la Ensenada que recoge abundante información de la fruticultura de El Bierzo muestran la extensión de estos cultivos agrícolas. En esta fuente aparece la diversidad de las producciones de frutales de pepita, manzanos y perales, de hueso, cerezas y melocotones y de fruto seco, almendras y castañas.

En la expansión de la fruticultura influyeron las clases privilegiadas, el pago de impuestos con estos frutos obligaba a plantar cultivos leñosos; como se observa en las cantidades que percibe la iglesia con los diezmos y el obis- 
pado de Astorga del que depende la comarca de El Bierzo; en el término municipal de Ponferrada en la localidad de San Esteban de Valdueza pagan los diezmos al cura por un quinquenio las siguientes cantidades de producción frutícola: "tres libras de almendras, diez arrobas de ciruelas, seis arrobas de manzana, dos arrobas de peras, seis de melocotones, cuatro quartales de castañas, ocho arrobas de cerezas, dos de guindas, un quartal de nueces".

Las transformaciones que se han producido en época reciente en el paisaje de fruticultura han implicado el abandono de los cultivos menos rentables y que no se adaptaban a las exigencias del mercado; aunque se mantendrán algunas producciones orientadas al autoconsumo, con unas técnicas de cultivo tradicionales.

Las principales especies de fruticultura, las podemos agrupar en tres tipos: los frutales de pepita, los de hueso y los frutos secos. Entre los primeros predominan las superficies de cultivo ocupadas por el manzano y el peral, aunque también hay algunos membrillos. En los de hueso son los cerezos los que están más extendidos aunque siguen conservándose en los huertos familiares algunos ciruelos. En los últimos, el más extendido es el castaño porque tiene unas condiciones ecológicas más favorables en toda la comarca; aunque en la actualidad se ha producido una regresión por las enfermedades de la tinta, el chancro y los incendios forestales (Agustí, 2004:32); y otros cultivos de frutos secos como los almendros se extienden por zonas dedicadas al cultivo del viñedo y nogales por las zonas más húmedas están en regresión.

Cuadro 1. Las principales especies de frutales en El Bierzo

\begin{tabular}{lll}
\hline Tipos de frutales & \multicolumn{1}{c}{ Principales especies } & Marcas de calidad \\
\hline $\begin{array}{l}\text { Frutales de Pepi- } \\
\text { ta }\end{array}$ & Peral, manzano, membrillero & $\begin{array}{l}\text { D.O. Manzana Reineta del } \\
\text { Bierzo, M.G. Pera Conferencia } \\
\text { del Bierzo }\end{array}$ \\
Frutales de hueso & $\begin{array}{l}\text { Cerezo, ciruelo, melocotonero } \\
\text { Frutos secos }\end{array}$ & $\begin{array}{l}\text { Almendro, avellano, nogal, cas- } \\
\text { taño }\end{array}$ \\
Otros frutales & Higuera, olivo & M. de Castaña del Bierzo \\
\hline
\end{tabular}

FUENTE: Consejos Reguladores, 2011. Elaboración propia.

En el área central de la cuenca del Bierzo, con los suelos más fértiles y un clima más favorable (CABERO, 1990: 39) es donde se ha producido una intensificación de la producción de fruticultura, las condiciones climáticas y los suelos fértiles en los depósitos sedimentarios del terciario y cuaternario en el fondo de la depresión a una altitud de 400-800 metros favorecen la intensificación agraria. Los regadíos tradicionales se han modernizado con la construcción de los canales del Bierzo Alto y del Bierzo Bajo que aprovechan las aguas del río Sil. 
La producción de fruticultura se va a modificar con la transformación de tierras de secano en regadío, y las parcelas se dedicarán exclusivamente al cultivo de frutales, los sistemas de plantación y poda tenderán a conseguir una mejor rentabilidad de los cultivos. En las zonas de secano están los cerezos y castaños.

\section{EL PAISAJE DE LA FRUTICULTURAL EN EL BIERZO: UNA MODERNIZACIÓN LIMITADA EN EL ESPACIO}

\section{III.1. El impacto del regadío en el paisaje agrario}

Fotografía 1. Canal Bajo de El Bierzo y en las inmediaciones parcelas de regadio y segundas residencias

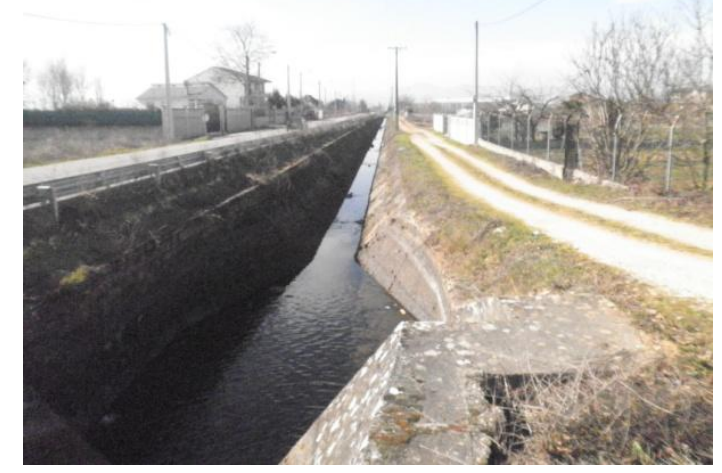

FuENTE: José María San Román, 2001, Carracedelo, León.
Las políticas hidráulicas que se impulsan en España a comienzos del siglo pasado incluirán los proyectos de regadío en El Bierzo (GIL, 2001: 8). Pero será en 1934 durante la II República con el "Plan General de Regadíos de El Bierzo", cuando se materialicen los proyectos de regadío en la comarca, comienza la construcción del Canal Bajo de El Bierzo que recoge las aguas del Sil en el embalse de Fuente del Azufre, en las inmediaciones de la ciudad de Ponferrada. Durante la Guerra Civil de

1936 a 1939 se paralizan las obras. Terminado el conflicto bélico será necesario esperar hasta el periodo 1949-1952 para que se finalice el primer tramo de esta infraestructura de riego, que se completará en 1956. La ampliación y modernización del regadío modifica el paisaje agrario de El Bierzo; del policultivo con frutales, hortalizas y cereales, se avanza hacia una especialización en los cultivos, en algunos casos con explotaciones mayores y orientadas hacia el mercado. Con este objetivo se construye un segundo canal de riego, el Canal Alto, con un trazado casi paralelo al anterior y que llevará también agua a los cultivos de la hoya berciana.

Este Canal Alto recoge las aguas del embalse de Bárcena construido en los años 1960, mejorando las posibilidades de utilizar el agua embalsada para regadío o abastecimiento urbano. Por lo tanto la construcción de estos dos canales de regadío de El Bierzo, el Canal Alto y el Canal Bajo con un traza- 
do casi paralelo y que llevará agua a los cultivos de la hoya berciana, permiten una modernización de la producción agrícola hacia la fruticultura, los cultivos industriales y la horticultura.

Los paisajes agrícolas de El Bierzo introducen con el regadío nuevos cultivos industriales como el tabaco y se realizan plantaciones de frutales de pepita, de manzanos y perales. Los sistemas de cultivo cambian en las pequeñas parcelas de frutales, se abandona el policultivo y se modifica el sistema de plantación, de poda y las variedades de cultivo. La orientación comercial es la que guiará a estas explotaciones de cultivos leñosos y para las que es necesario realizar inversiones a largo plazo. Desde que se realiza la plantación de los frutales hasta que comienza la producción pasan más de tres años y el periodo se incrementa hasta que están en plena producción.

Figura 3. Los canales y acequias de regadio en la "hoya de EL Bierzo".

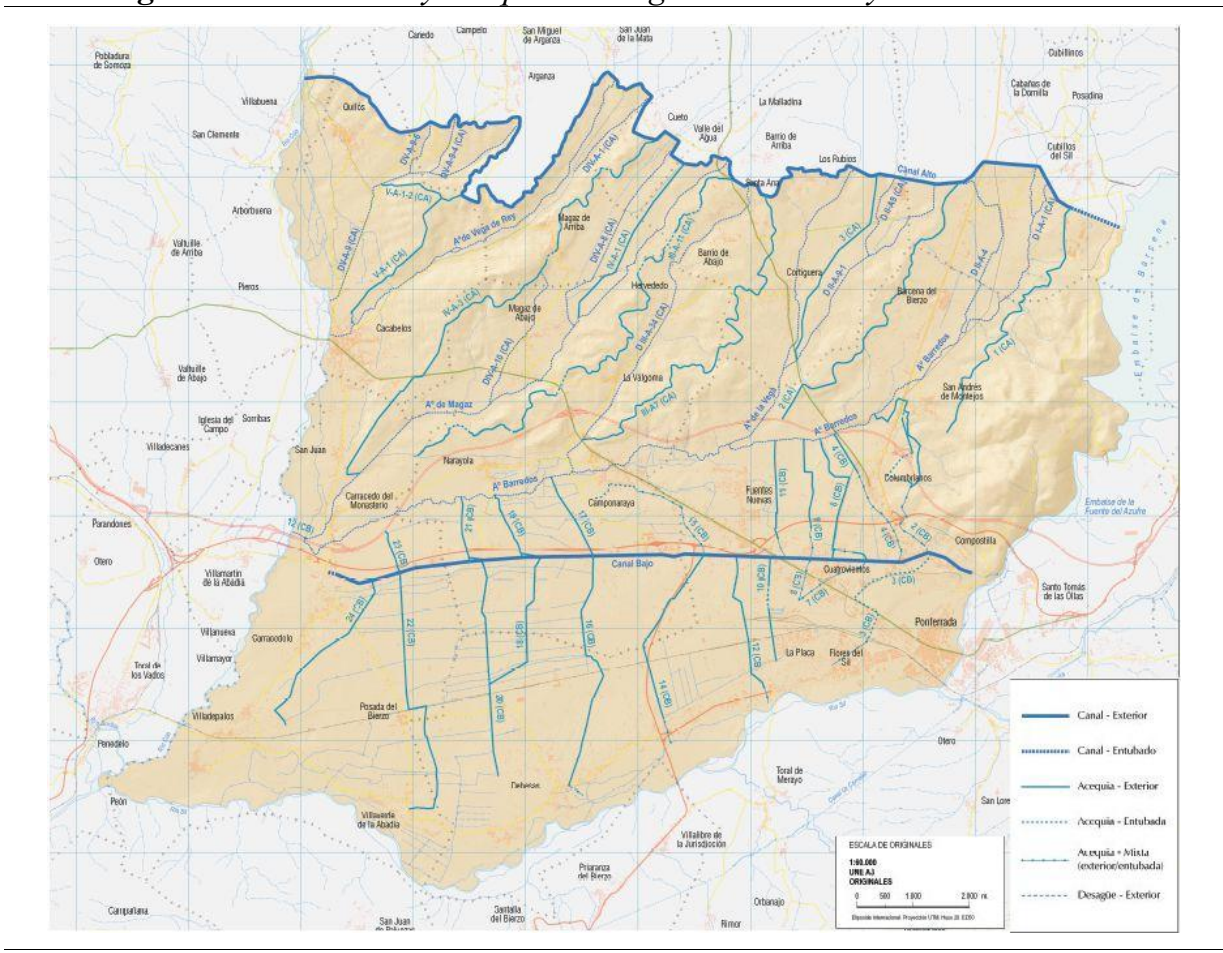

FuENTE: Ministerio de Medio Ambiente, 2007

El regadío del "Bierzo Bajo", ha modificado el espacio agrario de la hoya berciana. La red de canales y acequias llevan agua a las parcelas de cultivo, suministrando durante el periodo de aridez estival las cantidades necesarias para mejorar las cosechas. Las zonas de regadío están delimitadas por el río 
Sil en la zona este y sur, por el oeste el río Cúa afluente del Sil y por el norte es el mismo Canal Alto de El Bierzo, que tiene un trazado siguiendo la topografía de la zona (FIGURA 3). La superficie de regadío tiene forma cuadrangular y está separada el área que utiliza el agua del Canal Alto y el Canal Bajo por el arroyo de Barredos, que actualmente está canalizado para evitar inundaciones.

El espacio que incluye la zona de regadío de los dos canales es el que tiene las condiciones más favorables por la altitud de 400 a 500 metros, y su topografía más plana. Las obras de construcción del Canal Alto comienzan en los años 1950 y finalizan el último tramo de esta infraestructura en 1975. Recoge las aguas en el río Sil en el embalse de Bárcena, en el municipio de Cubillos del Sil, el sinuoso trazado se adapta a las condiciones que impone el relieve. El trazado podemos decir que es paralelo al Canal Bajo de El Bierzo, vierte las aguas sobrantes de regadío en el Cúa afluente del Sil en el municipio de Cacabelos. La zona de tierras de regadío se extiende al sur del trazado del canal, al norte las condiciones topográficas y edáficas lo impiden. Al finalizar las obras de construcción del pantano de Bárcena, se inundan los núcleos de Bárcena del Río y Posada del Río, y es necesario desplazar a sus habitantes. Con el objetivo de alojar a esta población y modernizar la producción agraria se elabora el Plan General de Colonización de la Zona Regable en 1963. El Instituto Nacional de Colonización traslada a los habitantes de estas poblaciones y a los afectados por el embalse de Campañana a los nuevos núcleos de Bárcena del Bierzo y de Fuentes Nuevas pertenecientes al término municipal de Ponferrada, y a Posada del Bierzo en el municipio de Carracedelo. Con este Plan de Colonización se aloja a los habitantes desplazados, entregando a cada familia una vivienda y las parcelas de cultivo en las zonas de regadío. La construcción y plano de estos núcleos es similar al de otras zonas de España con este tipo de pueblos de colonización, que contrasta con el hábitat tradicional de El Bierzo por el diseño del plano, la tipología de las viviendas y los materiales empleados en su construcción.

La superficie que se puede regar con los dos canales de El Bierzo es la más elevada del noroeste de la península, con el Canal Alto 6.958,13 has. a las que es necesario sumar las del Canal Bajo 5.799,20 has., por lo tanto la superficie de regadío en la fosa tectónica berciana alcanza las 12.757,33 has.; aunque la superficie inscrita es notablemente inferior se reduce a 5.072, 00 has. En esta zona tiene una gran extensión la superficie del viñedo, que en algunos casos está plantado en los lugares de mayores pendientes, pero en otros casos en parcelas que podrían ser de regadío. En el mapa vemos las parcelas de frutales de pepita que se extienden por toda el área incluida en el espacio de regadío. Algunas estaban ocupadas por el monte como la finca 
del Instituto Nacional de Colonización en el municipio Carracedelo, que es roturado y preparado para el cultivo. Las características edáficas influirán en la distribución de los cultivos, los suelos más pedregosos para los frutales y los suelos más profundos de mayor fertilidad para hortalizas y los cultivos industriales.

Las transformaciones del regadío son perceptibles en el paisaje agrario de la hoya berciana desde finales de los años 1960. En 1968 las cifras de frutales por especies muestran la transformación que se estaba produciendo con el regadío: el número de árboles dispersos por especie son de cerezo 2.367, almendros 7.408, manzanos 22.860, peral 50.000 árboles pequeños y 4.352 grandes (MANTERO, 1972: 52) y en las nuevas plantaciones de frutales de pepita en las parcelas que utilizan el agua de los canales 800.000 árboles. Corresponden a perales de las variedades de Limonera, Ercolini y de manzanos predominan la variedad de manzana Golden Delicious, y que recientemente a su vez se han sustituido por las variedades que tienen reconocidas las marcas de calidad.

\section{a. Las claves de la intensificación agraria: el regadío}

En los datos del CUADRO 2, comprobamos la especialización de la fruticultura berciana con las plantaciones de manzanos y perales.

En el paisaje agrícola de fruticultura de El Bierzo, si analizamos el número de explotaciones de la comarca y las comparamos con el total regional y provincial, comprobamos que el $18,98 \%$ de las existentes en Castilla y León se localizan en la hoya berciana y el $64,13 \%$ del total provincial. Pero son los paisajes de la fruticultura de regadío los que resultan más singulares, muestran una mayor concentración espacial, una de cada cuatro explotaciones de este tipo de la

Fotografía 2. Parcela de regadío con una plantación de frutales en espaldera en la hoya de El Bierzo

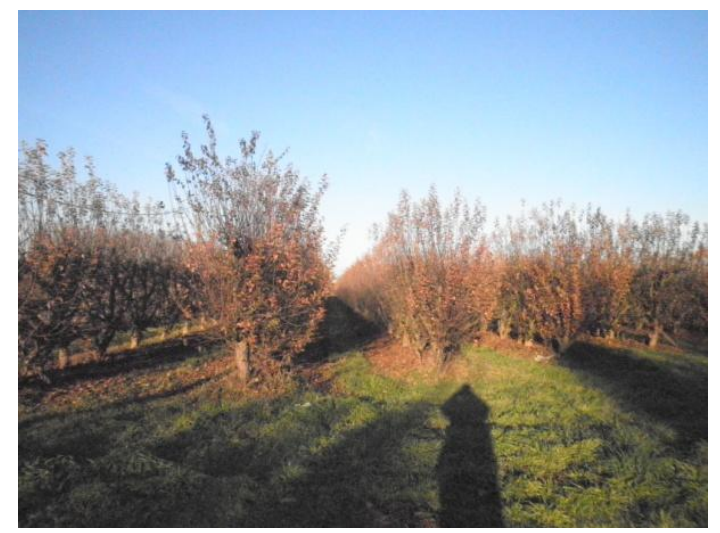

FuENTE: José María San Román, 2001, Carracedelo, León.

región, se localiza en este tramo del valle del Sil y en el caso de la provincia aumenta el porcentaje, una de cada dos explotaciones, cifras que podemos 
expresar de otro modo el $24,28 \%$ de las regionales y el $57,23 \%$ de las que se localizan en la provincia de León.

Los paisajes de fruticultura de regadío son "singulares" en esta comarca del oeste de Castilla y León, los datos de la superficie de regadío ocupada por frutales que equivale al $41,97 \%$ de la superficie regional y al $88,24 \%$ de la superficie de la provincia de León. Una imagen que contemplamos al realizar el Camino de Santiago o desplazarnos por la A-6, en los municipios de Ponferrada, Camponaraya y Carracedelo las numerosas parcelas plantadas de manzanos y perales y la infraestructura de regadío con los canales y acequias.

Figura 4. Parcelas de frutales de pepita en la zona de regadío.

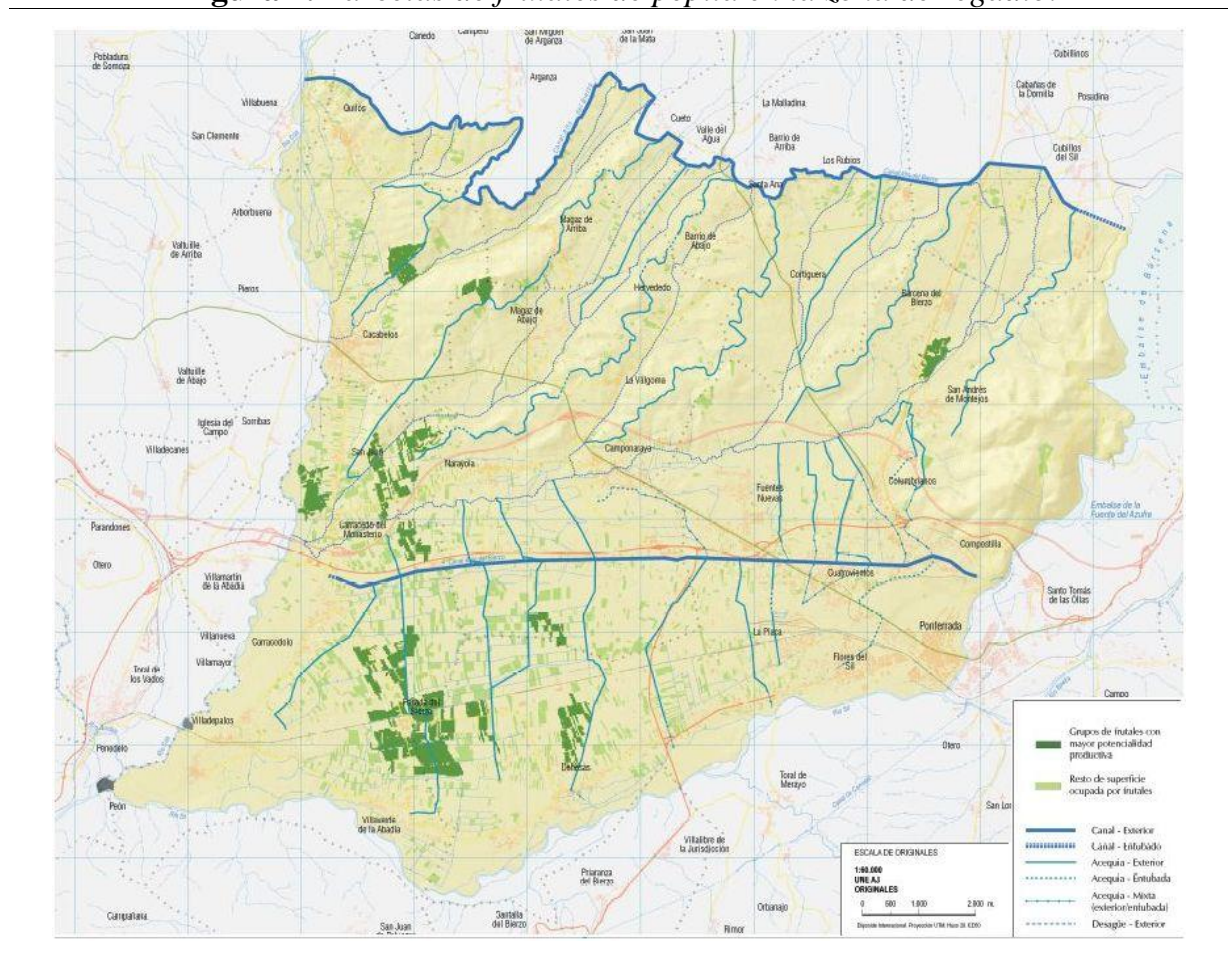

FUENTE: Ministerio de Medio Ambiente, 2007

Estas explotaciones de frutales son de reducido tamaño, dirigidas en un elevado porcentaje por agricultores a tiempo parcial que están empleados en otros sectores productivos o jubilados de actividades no agrarias, mayoritariamente de la minería del carbón o de la energía. La localización de las tierras de cultivo en la zona de mayor accesibilidad de la Comarca y la proximidad a la ciudad de Ponferrada, ha favorecido esta agricultura a tiempo 
parcial. Los agricultores que no tienen rentas distintas de la actividad agraria son muy pocos, dadas las posibilidades de empleos mejor remunerados en otros sectores de actividad. Por ello predominan las unidades de producción de 1 a 5 has. que totalizan 1.319 explotaciones, con una superficie de 625 has. y de regadío 765 explotaciones con una superficie de 473 has.

El minifundismo aumenta cuando analizamos la trama parcelaria, dado que la mayoría de las explotaciones contabilizan más de dos parcelas. Un ejemplo son las nuevas plantaciones de frutales que solamente pueden poner dos filas de frutales en espaldera por el reducido tamaño. Produciendo una imagen contrastada de diminutas parcelas con modernas plantaciones rectilíneas, de perales y manzanos, intercaladas con otras dedicadas a hortalizas o abandonadas. Corresponde las parcelas de mayor tamaño a las que formaban parte de la finca de colonización del nuevo núcleo de población, Posada de El Bierzo, que se localiza en el municipio de Carracedelo (FIGURA 4). Por lo tanto las parcelas entregadas por el Instituto Nacional de Colonización son las que tienen las tienen mayor superficie. El tamaño de las parcelas influye en la rentabilidad de la explotación, por ejemplo en parcelas muy pequeñas no es rentable instalar sistemas antiheladas, y por otro lado dificulta las labores agrícolas si una explotación tiene repartidas las parcelas de cultivo por el término municipal.

Cuadro 2. Número de explotaciones y superficie de frutales de clima templado en El Bierzo y porcentaje sobre León y Castilla y León

\begin{tabular}{lrrrrrr}
\hline & \multicolumn{1}{c}{ Total Bierzo } & \multicolumn{2}{c}{ Secano } & \multicolumn{2}{c}{ Regadío } \\
\hline \multicolumn{1}{c}{ Explot. con tierras } & Expl. & Ha. & Expl. & Ha. & Expl. & Ha. \\
\hline$>=0.1-<1$ & 999 & 137 & 451 & 52 & 548 & 85 \\
$>=1-<5$ & 1.374 & 625 & 609 & 152 & 765 & 473 \\
$>=5-<10$ & 211 & 279 & 94 & 40 & 117 & 239 \\
Más10 has. & 74 & 396 & 28 & 30 & 46 & 366 \\
\hline Total & 2.658 & 1.437 & 1.182 & 273 & 1.476 & 1.164 \\
\hline \% Bierzo/Prov. León & 64,13 & 86,72 & 77,86 & 80,76 & 57,23 & 88,24 \\
\% Bierzo/Cast. y León & 18,98 & 25,95 & 14,83 & 9,88 & 24,28 & 41,97 \\
\hline
\end{tabular}

FuENTE: Censo Agrario, 1999, INE

A partir de los datos del CUADRO 3, observamos que predominan en la comarca de El las explotaciones dedicadas a la fruticultura, representan el $56 \%$, son un quinto de las explotaciones de la provincia de León, y se aproximan al cinco por ciento de las de Castilla y León. En cambio, los datos de la superficie ocupada muestran el reducido espacio de estos paisajes de manzanos y perales, que se extienden por el $1 \%$ de la provincia de León y el 0,10\% de la región de Castilla y León. La concentración territorial y la reducida superficie de frutales son características de este paisaje agrario que lo 
convierten en excepcional, comparado con otros cultivos como los cereales.

Cuadro 3. Porcentaje de las explotaciones de frutales de la comarca de El Bierzo sobre el total de El Bierzo, provincia de León y Castilla y León

\begin{tabular}{lrrrrrr} 
& \multicolumn{2}{c}{ Bierzo } & \multicolumn{2}{c}{ León } & \multicolumn{2}{c}{ Castilla y León } \\
\cline { 2 - 7 } Expl. con tierras & 56,05 & Ha. $(\%)$ & Expl. .(\%) & Ha. .\%) & Expl. .(\%) & Ha. .(\%) \\
\cline { 2 - 7 }$>=0.1-<1$ & 45,38 & 20,78 & 1,09 & 4,85 & 0,10 \\
$>=1-<5$ & 64,05 & 23,26 & 31,48 & 16,11 & 12,84 & 5,56 \\
$>=13$ & 30,76 & 12,48 & 9,92 & 3,10 \\
$>=5-<10$ & 75,27 & 36,88 & 12,91 & 3,24 & 3,36 & 0,73 \\
$>=10-<20$ & 76,81 & 35,29 & 4,10 & 0,61 & 0,90 & 0,13 \\
$>=20-<50$ & 73,77 & 38,96 & 1,38 & 0,21 & 0,19 & 0,03 \\
$>=50-<100$ & 42,86 & 13,90 & 0,57 & 0,05 & 0,04 & 0,00 \\
$>=100-<200$ & 62,50 & 44,20 & 1,02 & 0,38 & 0,06 & 0,02 \\
$>=200$ & 100,00 & 92,05 & 4,17 & 0,95 & 0,20 & 0,04 \\
\hline
\end{tabular}

FuENTE: Censo Agrario, 1999, INE

\section{b. La diversidad del paisaje: las plantaciones de manzanos y perales}

En la comarca las teselas de los paisajes agrarios las forman plantaciones de manzanos y perales con formas rectilíneas, intercaladas con parcelas sin cultivar, que en la comarca se denominan "a poulo", y con otras dedicadas a hortalizas, y muy pocas de cereales. También aparecen zonas de praderas que corresponden a lugares que están encharcados durante largos periodos, y con zonas dedicadas a cultivos de chopos próximas a los cursos fluviales o en otros a parcelas de regadío. Por lo tanto la geometría de estas pequeñas parcelas de frutales se incrustan en campos de cultivo con otros aprovechamientos, la clave de esta diversidad está en una estructura de la propiedad muy pequeña, no se ha realizado la concentración parcelaria. En algunos casos que se ha planteado se ha generado un movimiento de rechazo a esta medida tan necesaria para rentabilizar la producción agraria. También en algunos casos a pesar de la concentración siguen siendo explotaciones agrarias con varias parcelas de tamaño muy reducido. En otros casos, esta oposición está relaciona con las expectativas de cambio de uso en las parcelas, de agrario a urbano.

En la superficie de regadío de la comarca predominan los cultivos leñosos y alcanzan el $79,91 \%$, correspondiendo a manzanos el $48,23 \%$ y a perales los $31,68 \%$ de la superficie de la Comarca de El Bierzo, esta ampliación de los espacios de cultivo se ha producido en un contexto de regresión de los cultivos industriales, el tabaco y con un incremento limitado de las parcelas plantadas de hortalizas, pimientos. La distribución que aparece en el gráfico ilustra estos datos de los cultivos.

Estos datos del CUADRO 4 muestran la concentración de la fruticultura de 
regadío en dos especies, manzanos en los que predomina la variedad Reineta y perales de la variedad de Pera Conferencia, variedades que concentran la zona de cultivo en tres municipios de la comarca, Camponaraya 7,73\%, Carracedelo $46,47 \%$ y Ponferrada $25,72 \%$ en los que las condiciones topográficas, edáficas y climáticas favorecen el cultivo. La construcción de los dos canales de regadío como hemos señalado ha impulsado la dedicación a las manzanas reinetas y a la pera conferencia en este espacio.

Cuadro 4. Superficie de regadío por cultivos leñosos de la comarca de El Bierzo

\begin{tabular}{lrrrrrr}
\hline \multirow{2}{*}{ Municipios } & \multicolumn{3}{c}{ Superficie en has. } & \multicolumn{3}{c}{ \% sobre el total Bierzo } \\
\cline { 2 - 7 } & Manzano & Peral & Total & Manzano & Peral & Total \\
\hline Camponaraya & 32 & 38 & 70 & 3,53 & 4,19 & 7,73 \\
Carracedelo & 271 & 150 & 321 & 29,91 & 16,56 & 46,47 \\
Ponferrada & 134 & 99 & 233 & 14,79 & 10,93 & 25,72 \\
\hline Total municipios* & 437 & 287 & 624 & 48,23 & 31,68 & 79,912 \\
\hline Total Bierzo & 519 & 332 & 906 & 100 & 100 & 100 \\
\hline
\end{tabular}

*En total municipios solamente están incluidos los términos municipales de Camponaraya, Carracedelo y Ponferrada.

FuENTE: C. de Agricultura y Ganadería. Junta de Castilla y León. Documentos 1-T. Año 2007

En estos municipios es donde se encuentran las principales empresas dedicadas a la producción y la transformación de frutas. En los datos aparece la hegemonía de Carracedelo por esa posición favorable para el cultivo, pero también por la política de colonización con la instalación del núcleo de Posada de El Bierzo y la superficie de regadío favorable para este tipo de cultivos en la zona de estudio (FIGURA 5).

Figura 5. Superficie de regadio de frutales de pepita en El Bierzo.

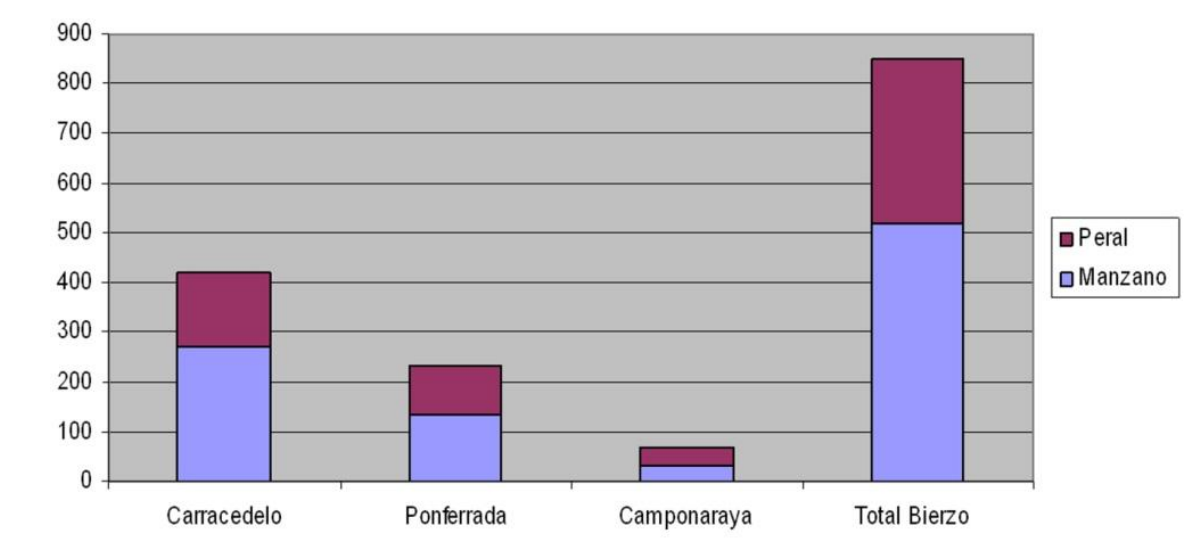

FuENTE: Consejería de Agricultura y Ganadería de la Junta de Castilla y León. Documentos 1T. Año 2007 
En la comarca predominan los manzanos con 519 has. y los perales con 332 has., distribución que aparece en los tres municipios más frutícolas con 437 has. y 287 has. Estas diferencias entre los frutales de pepita como analizaremos tienden a modificarse con un incremento de la superficie de perales.

Cuadro 5. Superficie de regadío de perales que aún no produce en has.

\begin{tabular}{lrr}
\hline \multicolumn{1}{c}{ Municipios } & Has. & $\%$ \\
\hline Cacabelos & 12 & 13,33 \\
Camponaraya & 10 & 11,11 \\
Carracedelo & 30 & 33,33 \\
Ponferrada & 25 & 27,78 \\
\hline Total El Bierzo & 90 & 100 \\
\hline
\end{tabular}

FUENTE: Consejería de Agricultura y Ganadería de la Junta de Castilla y León. Documentos 1T. Año 2007

Estos datos del CUADRO 5, muestran el incremento de la superficie plantada de perales porque resulta más rentable una parcela de estos árboles que una de manzanos. Las favorables condiciones de cultivo de la variedad de pera conferencia que por las características climáticas consigue unas calidades superiores a otras zonas y además los costes de producción son más reducidos al afectarle menos las plagas que a los manzanos. Además de esta variedad de pera conferencia, existen menos competidores en el mercado. Por lo tanto se realizan nuevas plantaciones de esta fruta de pepita, se arrancan manzanos de la variedad de Golden Delicious o de cerezos que no están incluidas en marcas de calidad.

Los cambios en las plantaciones de frutales no conlleva un incremento en la superficie de las parcelas, y sigue predominando la estructura minifundista y una mezcla de usos agrarios, urbanos e industriales. Los espacios industriales y las residencias secundarias o principales, se extienden siguiendo los ejes de comunicaciones. La localización en esta área de los principales Polígonos Industriales de la comarca de El Bierzo en la última década ha contribuido a dificultar la concentración parcelaria.

\section{Los paisajes agrarios de cerezos y de "soutos" de castaños}

Dentro de la fruticultura de la comarca de El Bierzo el proceso de intensificación en el cultivo de los frutales de hueso, los cerezos ha sido paralelo al de los manzanos y perales. Pero los problemas en la comercialización de la producción y la ausencia de una marca de calidad para este fruto ha disminuido el interés por este cultivo.

En el caso de la producción de castañas, la evolución de este cultivo ha sido distinta. Las zonas plantadas de castaños, "los soutos", han experimenta- 
do un proceso de abandono paralelo a los cambios que se producen en las zonas rurales a partir de los años 1960. Pero recientemente se ha producido un interés por este cultivo al incluirse las castañas de El Bierzo dentro de las marcas de calidad de los productos agrarios.

\section{a. La dispersión de los paisajes de cerezos}

Fotografía 3. Los cultivos leñosos en El Bierzo. Cerezos en flor en las inmediaciones de una acequia y cultivo de viñedo. Fotografía de Santiago Álvarez.

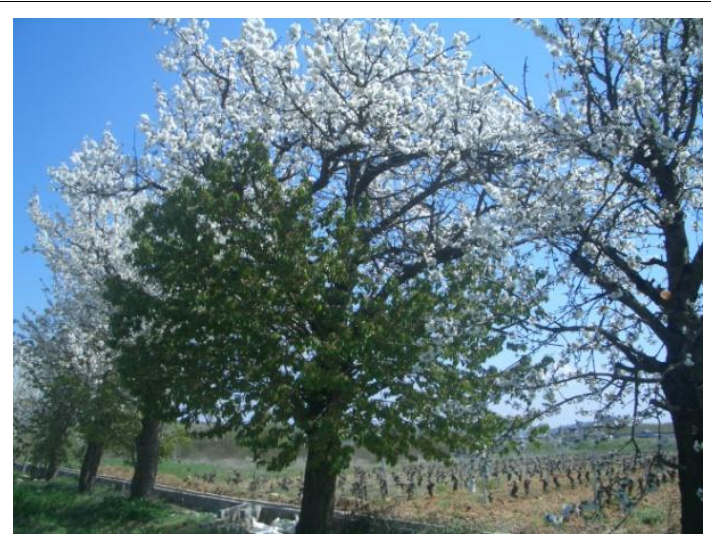

FUENTE: Santiago Álvarez, 2010, Ponferrada, León.
En el paisaje frutícola de hueso, están los cerezos. La distribución a escala municipal, muestra que los seis municipios en los que predominan los cerezos se incluye a los tres de la fruticultura de pepita, Camponaraya, Carracedelo y Ponferrada, a los que añadimos los de Cacabelos, Cabañas Raras y Arganza.

En los cerezos la modernización de las explotaciones ha sido más limitada, continúan en un porcentaje elevado asociados con otros cultivos como el viñedo, o delimitando las parcelas con las plantaciones de cerezos. En los municipios de Cacabelos y Corullón están asociados a estos cultivos. Cuando se produce esta mezcla de cultivos, el principal es el viñedo y el secundario son los cerezos; en los que se realiza la recolección de las cosechas de cerezas dependiendo de los precios del mercado. Por este motivo no realizan los tratamientos adecuados a los árboles contra las plagas o las podas correspondientes, son explotaciones en manos de titulares a tiempo parcial y muy poco profesionalizadas.

La evolución del paisaje de cerezos ha estado influida por las posibilidades de comercialización. Por este motivo se han utilizado diversas variedades de cerezos, al adaptarse mejor a las condiciones climáticas y a su vez aprovechar las ventajas que ofrece el mercado, por los precios más altos en las variedades muy tempranas. Así hasta los años 1980, la variedad monzón, que en la comarca denominan francesa, era la escogida en las plantaciones que procedía de los viveros. Pero también se realizaban plantaciones mediante el sistema tradicional, se recogían en las zonas de monte cerezos que se plantaban en las parcelas de cultivo y posteriormente se injertaban con la variedad que consideraban más rentable. En esta década comienzan a realizar plantaciones con la variedad burlat, que permite obtener las cosechas en época 
más temprana y por lo tanto alcanzan precios más elevados en el mercado; en este periodo se modifica también el sistema de poda de los árboles para que tengan un menor porte y por lo tanto facilitar las labores de recolección. Los frutos de esta variedad son de color rojo oscuro que contrasta su colorido con el verde de los árboles.

Cuadro 6. Superficie de cerezos en El Bierzo has.

\begin{tabular}{lrrr}
\hline \multicolumn{1}{c}{ Municipios } & Regadío has. & Secano has. & Total municipal \\
\hline Arganza & 5 & 2 & 7 \\
Cabañas Raras & 8 & & 8 \\
Cacabelos & 8 & 3 & 11 \\
Camponaraya & 8 & & 8 \\
Carracedelo & 5 & 2 & 7 \\
Castropodame & & 2 & 2 \\
Ponferrada & 4 & 2 & 6 \\
Sancedo & & 1 & 1 \\
Villadecanes & & 1 & 1 \\
\hline Total El Bierzo & 38 & 13 & 51 \\
\hline
\end{tabular}

FuENTE: Consejería de Agricultura y Ganadería de la Junta de Castilla y León. Documentos 1T. Año 2007

La producción de cerezas en El Bierzo en la actualidad alcanza los 300.000 kg., aunque en el municipio de Ponferrada en las zonas de cultivo del núcleo de Rimor en las faldas del monte Pajariel concentran una producción de $50.000 \mathrm{Kg}$., el $17 \%$ según fuentes del sector. Las favorables condiciones climáticas de esta zona se unen a las estrategias productivas y comerciales, que según el período de maduración de los frutos temprano o tardío realizan las plantaciones, en las zonas más soleadas o prefieren zonas de umbría. En cuanto a la estrategia comercial de vender la producción desde finales de mayo cuando maduran las primeras cosechas y las últimas en el mes de junio o comienzos de julio con las variedades más tardías (para concretar fechas desde el 20 de mayo hasta el 11 de julio) consiguen condiciones más ventajosas en los mercados, especialmente con las tempranas y las condiciones climáticas adversas por heladas o tormentas de granizo, pero afectan de forma diferente a cada variedad de frutales como hemos señalado y dependen del tamaño del fruto y las condiciones de maduración.

\section{b. Los paisajes de "sotos" de castaños}

En los paisajes de fruticultura de secano analizamos los sotos de castaños en los que predomina como principal orientación la obtención de fruto.

El paisaje agrícola de los castañares ocupa una amplía extensión en la comarca y una gran parte de estos "soutos" de castaños se han mantenido du- 
rante varios siglos ocupando ese espacio, dado que son árboles muy longevos y podían cultivarse el suelo. Ha retrocedido por el abandono de los que estaban más alejados ya que era más difícil la recolección del fruto por las elevadas pendientes y también por la sustitución por otros cultivos como el viñedo y los regadíos.

Figura 6. Localización de los sotos de castaños. Observamos que en El Bierzo Bajo ocupan muy poco espacio.

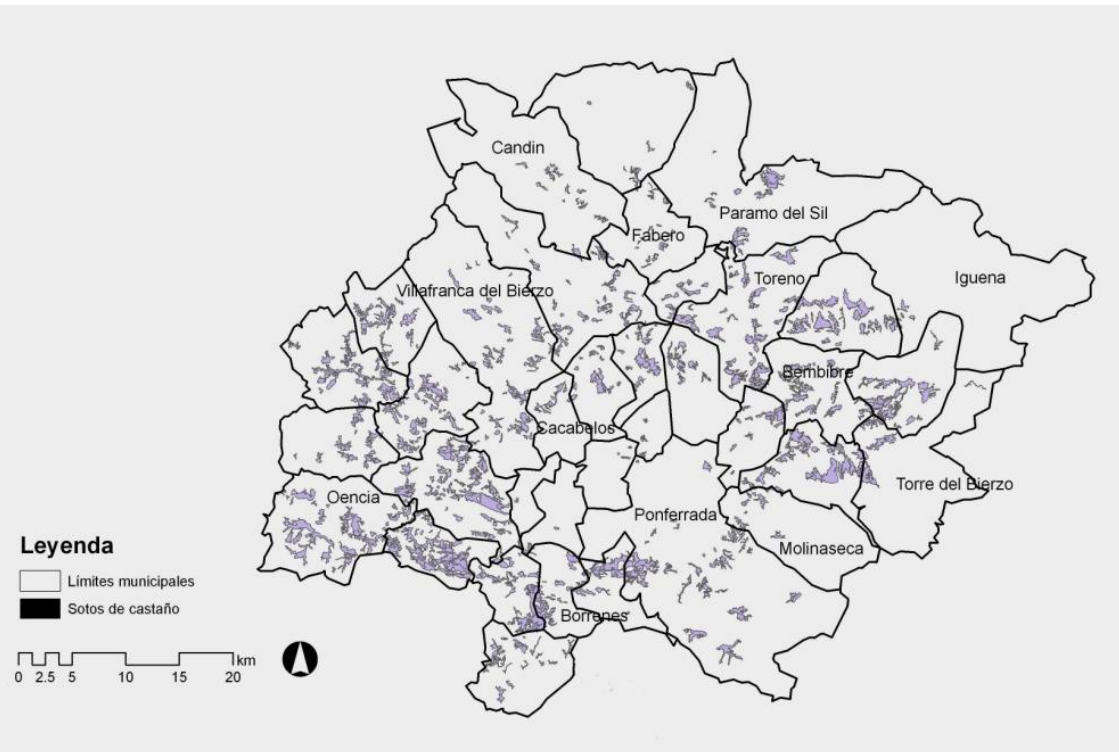

FuENTE: FERNÁNDEZ, A. (2010)

Los sotos de castaños se localizan a unas altitudes de $400 \mathrm{~m}$. hasta los 950 $\mathrm{m}$., por lo tanto en casi toda la comarca se pueden realizar plantaciones de castaños exceptuando las zonas de mayor altitud correspondientes a la orla montañosa (FIGURA 6), pero sin alcanzar las zonas de más altitud y en algunos valles de montaña (ÁlLVAREZ ET AL., 2010:53). Podemos señalar que han desaparecido los "soutos" de castaños de la zona de regadíos de la fruticultura intensiva que hemos analizado quedando solamente algunos árboles aislados. Se localizan los sotos en las zonas de pendientes más pronunciadas (MARTÍN, 1987:36).

El paisaje de los sotos es muy representativo de la comarca de El Bierzo, durante el otoño por el color marrón o amarillento de las zonas que están plantados de castaños y que le dan al paisaje una singularidad frente a otras especies, en la primavera y el verano con el color verde, durante el verano la flor del castaño también impregna de olores el paisaje y en el invierno cuan- 
do están desprovistos de hojas y contrastan con zonas de matorral o con otras zonas de hoja perenne. Son los últimos frutos que se recogen, desde la primavera hasta el otoño.

La difusión del castaño como hemos señalado se realiza durante el Imperio Romano o al menos se amplía la zona de cultivo para alimentar a la población dedicada a la actividad minera. En los "soutos de castaños" se obtenía además del fruto también leña, madera y con la hojarasca y los erizos materia orgánica para las parcelas de cultivo.

Los sotos de castaños alcanzan en El Bierzo una superficie de 19.298,95 has. de las cuales el 50\% continúan en explotación aunque sea de carácter extensivo, no se aprovecha por el ganado o no se cultivan cereales y no se utilizan para abono la hojarasca y los erizos. Las restantes superficies estarían en un proceso de degradación y progresivamente ocupados por el matorral o la vegetación arbórea (MANSO ET AL., 2010: 23).

Las variedades de castañas que se producen en los soutos son las de "parede", que también se cultiva en Asturias y Galicia y que se utiliza para elaborar castañas pilongas (castañas secas), "negral o injerta" esta variedad es apreciada porque las cosechas son tempranas y por el tamaño, esta variedad predomina en Las Médulas; la "galeguiña o navia", la "rapada o rapona", "de presa", la "marela"; la "raigona", "verdella " y "coruela" que son las principales variedades que producen los castaños de El Bierzo.

Los problemas de este cultivo están asociados a la crisis del mundo rural en los años 1950 y a pesar de que se han hecho algunas plantaciones de castaños en tierras que se han abandonado de otros cultivos, podemos decir que están en regresión los sotos de castaños.

El paisaje agrícola de los castañares ocupa una amplia extensión en la comarca y una gran parte de estos "soutos" de castaños se han mantenido durante varios siglos ocupando ese espacio. La tendencia en época reciente ha sido a abandonar aquellos que estaban más alejados de los núcleos de población y era más difícil recoger el fruto. Pero también en las zonas con otros cultivos leñosos más rentables, el viñedo y la fruticultura de pepita ha disminuido la superficie de castaños. En la zona central de la fosa tectónica encontramos algunos castaños aislados, sin formar masas continuas de "soutos" por la mayor difusión de las enfermedades de la tinta y el chancro, la competencia en los usos del suelo con otras producciones agrícolas como el viñedo y los cultivos de regadío que son más rentables y por condiciones ecológicas más desfavorables por las temperaturas más elevadas durante el verano y menor volumen de precipitaciones 
Los sotos de castaños están en regresión por el abandono de las explotaciones agrarias, el envejecimiento de la población rural, la pérdida de rentabilidad de todas las producciones que se obtenían, dedicándose exclusivamente a la recogida del fruto. Pero también por la propagación de enfermedades como la tinta, el chancro (Cryphonectria parasítica), los incendios forestales y el avance de las zonas de matorral y monte alto.

\section{La fruticultura: una apuesta por las producciones de calidad y la transformación en la industria agroalimentaria}

Los frutales de pepita, manzano y peral han evolucionado hacia la especialización agraria de la comarca. En los años 1960 el motor de la transformación en estos cultivos fue el regadío y en los años 1990 han sido las marcas de calidad para la manzana reineta, la pera conferencia y la castaña.

El sistema de riego a manta en las parcelas de regadío de manzana reineta blanca o gris que son las incluidas en la Denominación de Origen, y pera conferencia.

Solamente en las nuevas plantaciones que se están realizando de pera conferencia se ha introducido el sistema por goteo.

Por lo tanto el minifundismo con parcelas de muy reducido tamaño, y la lentitud u oposición en los procesos de concentración parcelaria son una barrera para el nuevo impulso modernizador de las explotaciones en el regadío y en otras técnicas de cultivo como los sistemas antihelada o granizo. En el municipio de Carracedelo la superficie concentrada en 1973 era de 929 has., que se distribuían antes de realizarla en diminutas parcelas de 0,079 has. y después alcanzaron 0,43 has., son pequeñas pero permiten mejorar los caminos de acceso y las acequias o canales de regadío. En Camponaraya se concentraron en 1984 un total de 742 has. las tierras de cultivo concentradas tenían una superficie de 0,17 has. por parcela y alcanzaron después 0,56 has., siguen teniendo tamaños muy pequeños, pero han permitido mejorar las labores agrícolas al tratarse de parcelas de con formas geométricas. En el municipio de Carracedelo están finalizando los trabajos de concentración de 454 has., en otros municipios como Cacabelos está paralizada por la oposición de los vecinos. El reducido tamaño obstaculiza la modernización de las explotaciones y los propietarios están interesados en conseguir en algunas de ellas usos no agrarios. Las pequeñas explotaciones o mejor dicho el reducido tamaño de las parcelas merma la rentabilidad de estos paisajes agrarios.

Los datos demuestran una evolución muy diferente en el caso de la pera conferencia y la manzana reineta, (CUADRO 7) mientras que han aumentado las superficies y las parcelas en las peras conferencia no se ha producido la 
misma situación en la manzana reineta que han disminuido el número de explotaciones de parcelas y de superficie, como ya citamos se están realizando nuevas plantaciones de perales. Los datos de parcelas por explotación en el 2004 muestran que en la pera conferencia hay 2,7 parcelas por explotación y en la manzana reineta un total de 2,5 parcelas por explotación. En los datos de 2010 corresponden a la pera conferencia 3,2 parcelas por explotación y para la manzana reineta, 2,3 por explotación.

Cuadro 7. Número de explotaciones, parcelas y has. de pera conferencia y manzana reineta y castañas inscritas en la marca de calidad

\begin{tabular}{lrrrrrr}
\hline & \multicolumn{3}{c}{2004} & & \multicolumn{3}{c}{2010} \\
\hline & Explo. & Parcelas & Has. & Explo. & Parcelas & Has. \\
\hline Pera Conferencia & 65 & 180 & 85,85 & 139 & 447 & 219,44 \\
Manzana Reineta & 173 & 445 & 217 & 120 & 280 & 130 \\
Castaña & -- & -- & -- & 22 & $75^{*}$ & 500 \\
\hline
\end{tabular}

FUENTE: Consejo Regulador para la D. O. Manzana Reineta, M.G. Pera Conferencia y M.G. Castaña Bierzo

Aunque hay otras variedades de peras que se cultivaban en los huertos y zonas de regadío de la comarca, y que no se han incluido en la marca de garantía.

Las condiciones climáticas y edáficas son favorables para las producciones de esta pera y es la que se comercializa hacia el mercado nacional con etiqueta de la marca de garantía. Las plantaciones se realizan en espaldera, a diferencia del sistema tradicional en el que los árboles podían crecer sin limitaciones.

Cuadro 8. Datos de producción de pera conferencia, manzana reineta y castañas

\begin{tabular}{lrrr}
\hline & $\begin{array}{c}\text { Producción kg. } \\
\text { Marca de Calidad }\end{array}$ & $\begin{array}{c}\text { Producción sin } \\
\text { Marca de Calidad }\end{array}$ & Total \\
\hline Pera Conferencia & 6.000 .000 & 800.000 & 6.800 .000 \\
Manzana Reineta & 4.000 .000 & 400.000 & 4.400 .000 \\
Castañas & 2.000 .000 & 6.000 .000 & 8.000 .000 \\
\hline
\end{tabular}

FuENTE: Consejo Regulador para la D. O. Manzana Reineta, M.G. Pera Conferencia y M.G.

Castaña Bierzo

La fruticultura de El Bierzo con marca de calidad es la que cuenta con más posibilidades de éxito en el mercado. En las manzanas tienen la Denominación de Origen Protegida para la manzana reineta concedida en diciembre de 1999, por la Junta de Castilla y León y ratificada en enero de 2001 por la Unión Europea. En las peras son las de la variedad de la Pera Conferencia de El Bierzo, la que está amparada en la Marca de Garantía desde febrero de 2004 y la más reciente es la Marca de Garantía de Castaña del Bierzo que se apruebó en julio de 2008. 
La comercialización de la producción de manzana y pera conferencia, está concentrada en tres empresas que almacenan y venden la producción al mercado nacional. En el caso de la castaña son cuatro empresas, aunque hay otras que procedentes de Galicia adquieren el producto en la comarca.

Estas producciones frutícolas se utilizan en las industrias agroalimentarias de la comarca, que elaboran conservas, postres, licores e incluso actualmente han ampliado la elaboración a los productos cosméticos a partir de esta producción de frutales. Por lo tanto la rentabilidad de las producciones agrarias aumenta cuando se transforma en las industrias artesanales o agroalimentarias mejorando el valor añadido de la producción.

\section{LA DINÁMICA SOCIOECONÓMICA RECIENTE EN LA HOYA BERCIANA}

Estos paisajes agrarios de fruticultura ocupan las zonas más pobladas y dinámicas de la depresión tectónica, especialmente la fruticultura de regadío que coincide con las zonas más urbanizadas y pobladas de mayor accesibilidad.

La comarca agraria de El Bierzo contabiliza 134.324 habitantes en el 2010, de los cuales 82.153 residían en los cuatro municipios con más relevancia de la fruticultura de pepita, Ponferrada, Cacabelos, Camponaraya y Carracedelo. El crecimiento de estos núcleos desborda las zonas de hábitat tradicional y se extiende siguiendo los ejes de comunicaciones que recorren la comarca, que influye en la dispersión de las viviendas principales y secundarias por los paisajes agrarios de cultivos leñosos, dado que el $61,16 \%$ de la población de la comarca reside en el 13,3\% del territorio. El ejemplo es el término municipal más poblado, Ponferrada con 68.767 habitantes, el principal centro urbano y funcional de la comarca y en el que se encuentra la ciudad de mayor tamaño, reside el $51,1 \%$ de la población de la comarca en el 10,02\% del territorio.

La articulación de este espacio se realiza mediante la red de infraestructuras las autovías A-6 y A-631, las carreteras N-VI y N-120 y la línea férrea Palencia-A Coruña. Además, la localización de los polígonos industriales, unido a los usos urbanos suponen una competencia con los usos del suelo para otras actividades productivas especialmente las agrarias. La expansión de la ciudad de Ponferrada por la hoya berciana y por la zona de huertas y cultivo de frutales es un ejemplo de urbanización del espacio agrícola.

La economía de la comarca desde 1918 con la llegada de la MSP (Minerosiderúrgica de Ponferrada), ha estado ligada al carbón y a la producción de energía, pero a partir de 1985 se produce el declive minero (Lois, R. et al.: 
2008:5). La consideración los paisajes agrarios que pueden rentabilizar las producciones cambia, y se considera una prioridad diversificar la economía impulsando las producciones agrícolas, y una forma de conseguirlo es mediante las producciones de calidad. A todo esto tenemos que añadir que la transformación de los productos agrarios consolidando a la industria agroalimentaria y el turismo rural apoyado en la diversidad de recursos de la comarca desde los paisajísticos a la elaboración de productos artesanales y en el paisaje, deben ser algunos de los sectores que contribuyan a dinamizar la estructura productiva. La producción agraria se convierte en una fuente de riqueza, por su orientación hacia el mercado e incluso por las posibilidades que ofrece en una situación de crisis la orientación hacia el autoconsumo. Muy necesaria la producción agraria por los procesos de crisis cíclicas de la minería, la última en los años 1990 plantea la necesidad en la fosa berciana de diversificar la economía.

\section{LA VALORACIÓN CULTURAL DEL PAISAJE}

Desde la mirada artística, los matices y cambios de los paisajes agrarios de El Bierzo ha sido contado por los autores románticos y especialmente por el escritor Gil y Carrasco que en sus obras: "El Señor de Bembibre" y "Bosquejo de un viaje a una provincia del interior", aparecen abundantes datos y descripciones pormenorizadas de la comarca. Hemos seleccionado los fragmentos que hacen referencia al paisaje de la fruticultura del insigne escritor, y también hemos recogido las de un contemporáneo Antonio Fernández y Morales con pormenorizadas descripciones de El Bierzo, y que su obra ha tenido muy poca difusión hasta época reciente. Estas citas las completamos con la visión reciente del paisaje de fruticultura que realiza Raúl Guerra Garrido.

Enrique Gil y Carrasco en "El Señor de Bembibre", describe el valle del Sil: "Entre norte y ocaso se divisaba un trozo de la cercana ribera del Sil, lleno de árboles y verdura, más allá del cual se extendía el gran llano del Bierzo, poblado entonces de monte y dehesas y terminado por las montañas, que forman aquel hermoso y feraz anfiteatro." (GIL, 1992: 97). Para citar en esta misma obra las higueras y frutales, que forman el paisaje de esta comarca.

El paisaje agrario de la comarca tiene una descripción pormenorizada en: "Bosquejo de un viaje a una provincia del interior", de los cultivos y el hábitat rural de EL Bierzo, " La cuenca deleitosa de Vilela dilataba a orillas del Burbia sus huertas y prados, sus campos de trigo y sus castañales y, a su frente, en su recogido seno de los montes subía, en lucida y desordenada gradería con sus higuerales y vergeles, el pueblo de Corullón coronada por 
un antiguo y alto castillo" (GIL, E., 1985:78). Las referencias son abundantes a este paisaje de la comarca y a otros rincones, como el valle del Oza, el paisaje del monasterio de Montes "Las huertas y los prados, los frutales y árboles silvestres, los emparrados que a veces extienden sobre el camino su rústico dosel," (GIL, 1985:101).

También otro de los autores bercianos contemporáneo de Gil y Carrasco, es Antonio Fernández y Morales, del que se han reeditado recientemente sus obras y que habían tenido una escasa difusión y eran poco conocidas, aunque paradójicamente tiene en el paisaje y la cultura del Bierzo el tema central.

El interés de Antonio Fernández y Morales por la poesía de paisaje queda reflejado en el poema, dedicado al Santuario de la Santísima Virgen de la Quinta Angustia en el municipio de Cacabelos: "Frondosas véigas, hortos e cortiñas/ Arrodeadas de beiróis espesos/ Xardiños á ribéiras e campiñas/ É sóutos por serpentes d água présos; / Arboledas, Pradéiras, holgas viñas" (FERNÁNDEZ, 2003:14).

Pero también en la poesía costumbrista muestra la fruticultura de la comarca. En el poema dedicado a los magostos, se hace referencia, a la importancia de esta celebración a comienzos del mes de noviembre cuando ya casi ha finalizado la recogida de las castañas: "n este mes en que ya trochos,/ revilvando - cos castañéiros,/ non van tirar os garduños,/ porque ya nada téin dentro/ os orizos, que fay póuco/ regañaban, é n o suelo/ pingaban negras castañas/. (...) $\mathrm{n}$ este mes $\mathrm{n}$ o que ya os figos quédanse fofos e o hielo, / os membrillos y acerolas/ recollen os confitéiros,/os merodos póinse roxos/é se póin os bruños negros"(FERNÁNDEZ, 2003:205-206).

Por último citamos a uno de los consagrados escritores que residen fuera de la Comarca, pero que en sus obras tiene las referencias más recientes al paisaje de El Bierzo, es Raúl Guerra Garrido. Narra con maestría y de forma pormenorizada los paisajes agrarios de la fruticultura berciana, aparecen en la siguiente descripción de los tipos de manzana. El texto que vamos a citar, corresponde a una de las obras de homenaje a Enrique Gil y Carrasco en "Viaje a una provincia interior" una referencia al paisaje de El Bierzo y a lo esencial de la fruticultura de la comarca: "Sea cual sea el punto de vista, no puede describirse un solo ángulo del Bierzo sin hacer mención de su fruta" para añadir a continuación: "Cenamos en la terraza, al aire libre del noroeste, y poco a poco la emoción del recuerdo cedió su lugar al de la fronda del paraíso terrenal en que nos encontrábamos; por entre y sobre los balaústres circundantes emergían las ramas de múltiples árboles, todas cargadas de frutos. Con tan sólo alargar la mano podía coger las más suculentas ciruelas claudias, brevas moradas, cerezas picotas, manzanas verde doncella y man- 
zanitas de la dama que son los aceroles, los rojos y los amarillos; y molestándome en bajar a la huerta seguir la serie en una larga variedad de higos, ciruelas, manzanas y peras de inolvidables redondeces" (GUERRA, 2008:3637). Posiblemente en la descripción de los tipos de manzanas queda ilustrada la riqueza y variedad de la producción de fruta en la comarca: "Me dije que, por mal que se dieran las cosas, un país que produce tal variedad de manzanas siempre tiene arreglo: la repinalda, de color pálido, de forma alargada y de sabor dulce y aromática; la agustina, redonda, pequeña, colorada y dulce; la tabardilla o reineta, grande, verdulenta y de sabor ácido; la nánjara, dulce, de color amarillo y poco sustanciona, la más economica; la calabacilla, medio alargada y medio dulce; buena para compota; la carueza, brava, diminuta, dulzona pero todavía verde" (GUERRA, 2008:37).

Las favorables condiciones ecológicas han permitido en el paisaje agrario de El Bierzo el cultivo de la fruticultura. Estos cultivos se intensifican con el regadío y la orientación comercial de las producciones. En la actualidad predominan cuatro especies de fruticultura: manzanos, perales, castaños y cerezos. Tienen marcas de calidad los frutos de las tres primeras, y las cerezas se estudia en un futuro la integración en alguna de estas figuras para mejorar las redes de distribución en los mercados. Estos paisajes han sido valorados desde la literatura especialmente por el escritor romántico Enrique Gil y Carrasco.

\section{BIBLIOGRAFÍA}

Álvarez, P., CÁMARA, A. y CASTEDO, F. (2010): «Técnicas culturales y selvícolas de manejo de los sotos de castaños», en Fernández-MAnso, A., MARTínez, C. NESPERAL, A. (Coord.), Un futuro para el castaño. Estudios sobre el castaño en la comarca de El Bierzo, 2010, León, Asociación A Morteira, 12-49.

Agustí, M. (2004): Fruticultura. Madrid, Mundi-Prensa.

BodELón, S (1998): «Carracedo en el siglo XVI»; Scripta, estudios en homenaje a Élida García García, Facultad de Geografía e Historia, Universidad de Oviedo, Oviedo.

CABERo, V. (1983): El espacio geográfico castellano-leonés. Valladolid, Ambito.

Cortizo Álvarez, J., Durany CAstrillo, P., García LóPez, D. y RedONDo VEGA, J Ma . (1988), «El Bierzo Bajo», en La provincia de León y sus comarcas (CABERO, V. y LóPEZ, L.), León, Diario de León, Fascículo 4, 57-72.

FERnÁndeZ, V. (Coord.) (2008): El Bierzo de Raúl. Ponferrada, Instituto de Estudios Bercianos.

FERnÁNDEZ, M., FERnÁndEZ, G., FERnÁndEZ, J. R. (2010): «El sistema de regadío del Bierzo». Ería. Revista de Geografía, No82, 159-169.

Fernández, A., Moya, B., Martínez, C., Nespral, A., Francés O., Valbuena, L. MARCOS, E., SAN ROMÁN, J.Ma . y RAMíREZ, J. (2007): «Plan de conservación de los árboles y arboledas monumentales de la comarca del Bierzo» en I Encuentro del día Forestal Mundial, Conservación y gestión del Arbolado Monumental, 
Ponencias, 21 de marzo de 2006, Ponferrada, Ayuntamiento de Ponferrada, 92103.

Fernández, A., Robles, J., Martínez, C:, Nesperal, A., Francés, O., Suárez, L. y ARIAS, R. (2010): «Análisis y diagnóstico territorial del castaño en la comarca de el Bierzo (León)» en FERnández-MAnso, A., MARTínez, C. NESPERAL, A. (Coord.), Un futuro para el castaño. Estudios sobre el castaño en la comarca de El Bierzo, 2010, León, Asociación A Morteira, 12-49.

FERnÁndeZ, F., VERdE Ma. C. Y ROdRÍGUEZ, A. (1998): «O Souto, un ecosistema en perigo», Santiago de Compostela, Servicio de Estudios e Publicacións, Consellería de Agricultura, Gandería e Política Agroalimentaria, Xunta de Galicia.

GARCíA FERnÁNDEZ, J. (1986): El Clima en Castilla y León. Valladolid, Ámbito.

GIL y CARRASCO, E. (1992): El Señor de Bembibre. Valladolid, Ámbito.

GIL y CARRASCO, E. (1985): Bosquejo de un viaje a una provincia del interior. León, Diputación de León.

FERnÁndeZ, A. (2003): Ensayos poéticos en Dialecto Berciano. Ponferrada, Instituto de Estudios Bercianos.

GuERrA, A., GUERRA, M. (2009): Evolución de la fruticultura y poda de los árboles frutales, Valladolid, Consejería de Agricultura y Ganadería.

LOIS, R.C., SAN ROMÁn, J.M ${ }^{\mathrm{a}}$ y ALDREY, J.A. (2008): «Impacto de la actividad minera en la población de los espacios de montaña: La pizarra y el carbón en las montañas galaico-leonesas». Ería. Revista de Geografía, n 75, 99-112.

LóPEZ, L. CoRTIZO, J. y LóPEZ, A. (2007): Población y Vivienda en la provincia de León, León, Servicio de Publicaciones de la Universidad de León.

Mantero, M. (1972): Análisis económico de la región de El Bierzo. León, Institución "Fray Bernardino de Sahagún" C.S.I.C.

MARTín, J.L. (1987): Poblamiento y actividad agraria tradicional en León, Valladolid, Consejería de Obras Públicas y Ordenación del Territorio.

MARTíneZ, J.E. (2008): «Las novelas del Bierzo de Raúl Guerra Garrido», en El Bierzo de Raúl (Fernández, V. Coord.). León, Instituto de Estudios Bercianos, $1^{\circ}$ ed., 13-74.

Mata Olmo, R. (2004): «Agricultura, paisaje y gestión del territorio», en Polígonos, Revista de Geografía, 14, 97-137.

MAYA, A. y FERNÁNDEZ, J. (1993): «Situación actual y perspectivas en el sector agrario de la provincia de León». Ería. Revista de Geografía, n³2, 214-223.

Molinero, F., AlARIO, M. y BARAJA, E. (2009): «Unidades Escalares en los Paisajes de la Agricultura de España», en Geografía, Territorio y Paisaje: Estado de la Cuestión, Actas del XXI Congreso de Asociación de Geógrafos Españoles. Ciudad Real, UCM-AGE, 913-926.

Redondo VegA, J.M. (2002): XVII Jornadas de Geografía Física, Secretariado de Publicaciones y Medios Audiovisuales. Universidad de León, Servicios de Publicaciones.

RODRÍGUEZ, M.C., DURANY, M (1998): «Ocupación y organización del espacio en El Bierzo Bajo entre los siglos V al X». Ediciones Universidad de Salamanca. Studia Historica, Historia Medieval, $\mathrm{n}^{\circ}$ 16, 45-87.

Silva, R. y Villar, A. (2009): «La Pluridimensionalidad del Paisaje como Criterio para la caracterización de los Paisajes de la Agricultura», en Geografía, Territo- 
rio y Paisaje: Estado de la Cuestión, Actas del XXI Congreso de Asociación de Geógrafos Españoles. Ciudad Real, UCM-AGE, 1371-1385.

Página Web y Fuentes

Publicación en línea: http://pares.mcu.es/ Catastro/servlets/ ServletContro-

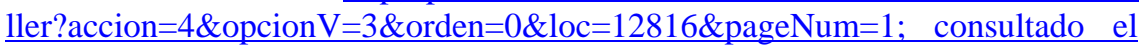
$10 / 01 / 2011$

Diario de León, 24/12/2006, 02/04/2006

La Crónica de León, 5/08/2009 